\title{
Invasive Fungal Infections in People Living with HIV/AIDS
}

\author{
Adriana Lemos de Sousa-Neto ${ }^{1,2}$, Denise Von Dolinger de Brito Röder ${ }^{2,3}$, \\ Reginaldo dos Santos Pedroso ${ }^{1,2}$ \\ ${ }^{1}$ Technical School of Health, Federal University of Uberlândia, Uberlândia, Minas Gerais, Brazil \\ ${ }^{2}$ Post-Graduation Program in Health Sciences, Medicine School, Federal University of Uberlândia, Uberlândia, Minas Gerais, \\ Brazil \\ ${ }^{3}$ Institute of Biomedical Sciences, Federal University of Uberlândia, Uberlândia, Minas Gerais, Brazil \\ Email:denise.roder@ufu.br
}

How to cite this paper: Sousa-Neto, A.L. Röder, D.V.D.B. and Pedroso, R.S. (2020) Invasive Fungal Infections in People Living with HIV/AIDS. Journal of Biosciences and Medicines, 8, 15-26.

https://doi.org/10.4236/jbm.2020.89002

Received: July 16, 2020

Accepted: September 6, 2020

Published: September 9, 2020

Copyright (c) 2020 by author(s) and Scientific Research Publishing Inc. This work is licensed under the Creative Commons Attribution International License (CC BY 4.0).

http://creativecommons.org/licenses/by/4.0/

\begin{abstract}
The increased incidence of invasive and opportunistic mycoses is probably related to the growth of the immunocompromised population, such as people living with HIV. This study is a literature review that aims to analyze the frequency of invasive fungal infections in people living with HIV. In most studies evaluated, Pneumocystis pneumonia was the most frequent invasive fungal infection among people living with HIV, and cryptococcosis was the second most frequent. Invasive fungal infections are associated with greater morbidity and mortality in people living with HIV. The most important highlighted information is that the lack of epidemiological data on fungal infections in the studied populations was reported by most studies. Therefore, there is a need for further studies to assess the frequency of invasive fungal infection in people living with HIV, which may serve as subsidies for the implementation of strategies for the prevention and management, with a consequent increase in the quality of life and reduction of morbidity/mortality in this population.
\end{abstract}

\section{Keywords}

Invasive Fungal Infections, HIV, Epidemiology, Invasive Mycoses,

Pneumocystis, Opportunistic Mycoses

\section{Introduction}

Human immunodeficiency virus (HIV) infection is still a public health problem, despite the global effort to reduce new cases of infection, discrimination, and mortality related to Acquired Immunodeficiency Syndrome (AIDS) [1]. The 
overall incidence of HIV infection reached its peak in 1997, with 3 million new cases. There was a decline between 1997 and 2005, and after that period, the annual incidence remained relatively constant. However, the number of people living with HIV has steadily increased, reaching 38.8 million in 2015 worldwide [2].

The year 1996 represented a milestone in the history of the treatment of HIV infection due to the availability, in several countries, of highly active antiretroviral therapy (HAART) with a combination of several antiretroviral medications, which provided a reduction of mortality with a decrease from 1.8 million deaths in 2005 to 1.2 million in 2015 in world statistics [1].

By contrast, although many countries have experienced decreases in mortality and in new HIV/AIDS cases, others have increased incidence of infection [2]. In Latin America, 79,000 to 130,000 people acquired HIV in 2018, a 7\% increase compared with 2010. Increases in incidence were seen in Brazil (21\%), Costa Rica (21\%), Bolivia (22\%) and Chile (34\%), according to UNAIDS [3].

In the Clinical Protocol and Therapeutic Guidelines for the Management of HIV Infection in Adults updated in 2017, the Ministry of Health of Brazil points out the emergence of opportunistic infections and neoplasms as defining characteristics of AIDS. These included pneumonia, neurotoxoplasmosis, cryptococcal meningitis, atypical or disseminated pulmonary tuberculosis, and retinitis caused by cytomegalovirus [4].

The epidemiology of invasive fungal infections (IFI) is not completely known when compared to other infections, but the subject deserves special attention due to its increased incidence, mainly in relation to diseases that cause immunodepression, such as AIDS [5]. More than $90 \%$ of the deaths arising from fungal infections are associated with species of one of the genera Cryptococcus, Candida, Aspergillus, or Pneumocystis [6].

According to Armstrong-James et al. [7], there are more than one million new cases of invasive fungal infection related to HIV-AIDS per annum and mortality reaches 500,000 worldwide. The mortality rate varies between $30 \%$ and $70 \%$ for cryptococcal meningitis, $10 \%-60 \%$ for histoplasmosis, $10 \%-30 \%$ for Pneumocystis pneumonia and $10 \%-33 \%$ for talaromycosis according to the place and study [7] [8]. Another infection, oral candidiasis, is common in untreated patients and has a high degree of morbidity [7].

The increased incidence of some of the invasive mycoses is probably related to the growth of the immunocompromised population, the increase in the number of solid organ and bone marrow transplants, and the use of immunosuppressive drugs [9] associated with the improvement of diagnostic technologies. In the era HAART, the IFI still occur in patients with HIV, mainly in those with low CD4+ count $\left(<200 \mathrm{~mm}^{3}\right)$; the existing clinical challenge is perceived in relation to fungal infections in patients that are severely immunocompromised [10].

In this way, the epidemiology of IFI in people living with HIV is important to direct the actions focused on their diagnosis, prevention, and treatment, being a 
strategy for improving the quality of life of this population. The present study aimed to approach the frequency of IFI in people living with HIV and the main fungal species evolved.

\section{Methodology}

\subsection{Type of Study}

This study consists of an integrative review of literature, that is a method of bibliographical research, which allows scientists to gather and summarize the scientific knowledge available on the subject in research. This type of study makes possible the evaluation and synthesis of the available scientific evidence that will contribute to the development of conclusions on the discussed thematic [11]. Six steps have been taken to prepare this study: establishing the guiding question and objectives of the research; definition of criteria for inclusion and exclusion of publications; search in the literature; analysis and categorization of studies; and presentation and discussion of results [11]. The question for this review was: "How frequent are invasive fungal infections in people living with HIV?" Based on the guiding question, the PRISMA flowchart model was used (Figure 1).
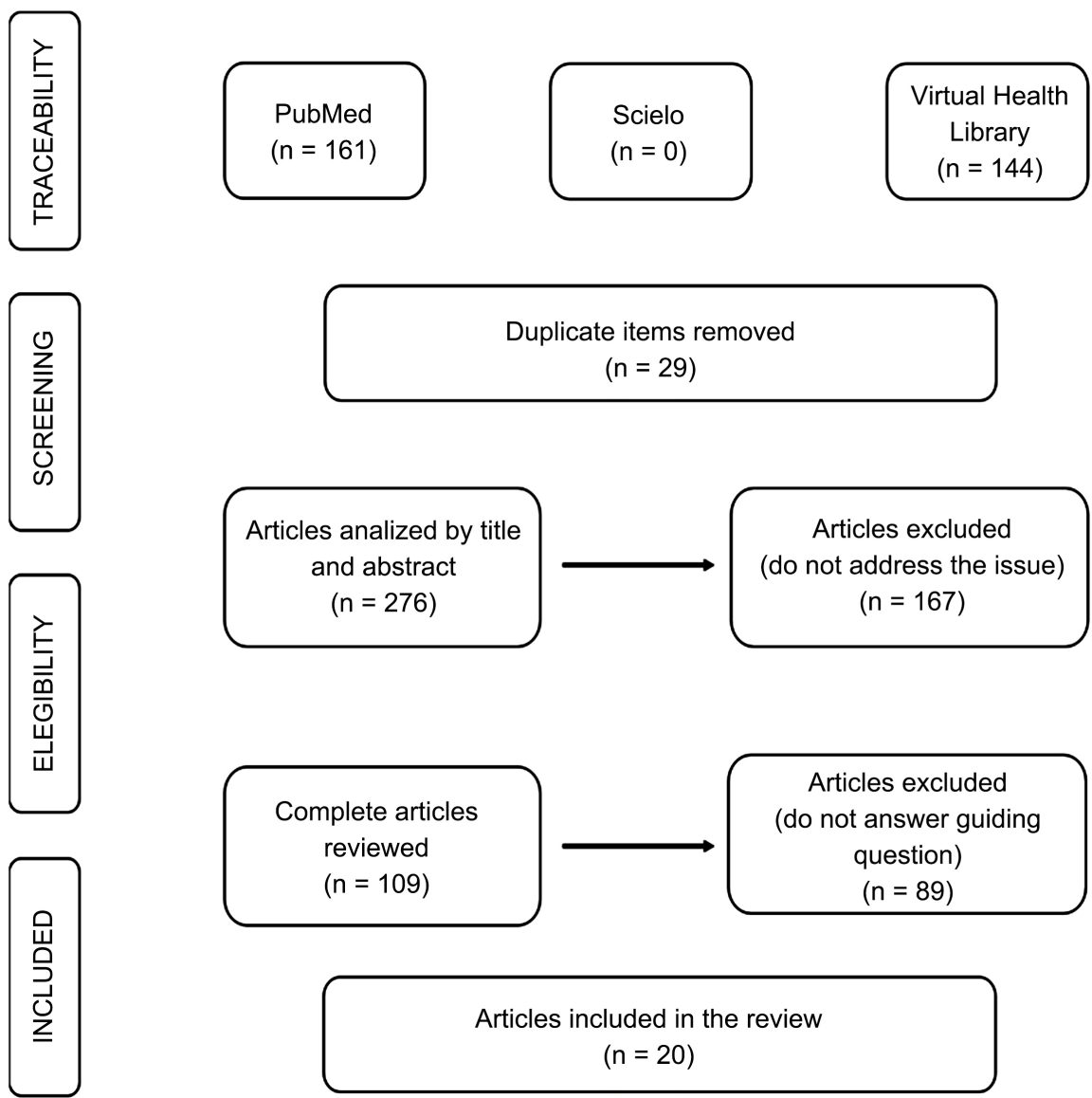

Figure 1. Flow of the selection process of the studies for the integrative literature review, elaborated based on the PRISMA recommendations. 


\subsection{Course of the Selection of Articles}

The search took place in May 2018 in the following databases and/or digital libraries: Virtual Health Library, Scientific Electronic Library Online (Scielo), and the PubMed portal; the Medical Literature Analysis and Retrieval System Online (Medline) from the association of descriptors in Health Sciences and Medical Subject Headings (MeSH) by means of the Boolean operator "AND": epidemiology; invasive fungal infections; and HIV. In the Medline/Pubmed search process, by the characteristics of this database, only the English descriptors were used. All the identified studies were initially evaluated by way of analysis of the titles and summaries. In the studies in which the reading of the title and summary was not sufficient for the application of the criteria of inclusion and exclusion, the article was read for inclusion or exclusion in the study.

The inclusion criteria were: publications that addressed invasive fungal infections in people living with HIV; published or available online in the period from January 2007 to April 2018 (10-years period); in the Portuguese, English, or Spanish languages; and were available free of charge for full Internet reading. Studies were excluded that did not fill in the previous requirements; literature review papers, case reports, dissertations, theses, book chapters, supplements or editor comments; articles that did not address the search theme; and the duplicate articles should be considered for posting only once. A data collection instrument was developed that met the following inclusion criteria: 1) year of publication, 2) authors, 3) country where the study took place, 4) study type, and 5) IFI more frequent in people living with HIV.

\section{Results}

The path traveled in the identification and selection of study components was described in Figure 1. The selective reading of the 305 articles found in Medline and Virtual Health Library were initially made with review by title and summary. Thirty-seven studies were selected from Medline, according to titles and summaries. Then, the full and critical reading of these texts was conducted, and six articles were selected. From the search conducted at the Virtual Health Library, 72 articles were chosen after reading titles and summaries, which were read. Among the articles, 14 were selected. Of the 109 articles selected in the two databases, 89 were excluded when the pre-established exclusion criteria for the study were applied. So, 20 articles composed the corpus of work.

\section{Characteristics of the Studies}

Nineteen $(95.0 \%)$ studies were published in the last 5 years. A broad geographical distribution is noted in the included studies, since three (15.0\%) were carried out in Africa, four (20.0\%) in Latin America, one (5.0\%) in North America, six (30.0\%) in Europe, and six (30.0\%) in the Asian continent (Table 1). Sixteen (80.0\%) studies were epidemiological descriptive, two (10.0\%) were retrospective descriptive, one (5.0\%) prospective descriptive, and one (5.0\%) randomized. 
Table 1. Most frequent invasive fungal infections in people living with HIV according to different studies.

\begin{tabular}{|c|c|c|c|c|c|c|}
\hline Year & Publications & Local & Type of study & Most frequent IFI & $\begin{array}{c}\text { Candidiasis } \\
\text { (not invasive) })^{*}\end{array}$ & $\begin{array}{l}\text { Use of } \\
\text { HAART }\end{array}$ \\
\hline 2009 & [14] & Italy & Descriptive retrospective & Pneumocystis pneumonia & not & - \\
\hline 2014 & [42] & France & Descriptive epidemiological & Pneumocystis pneumonia & not & - \\
\hline 2014 & [10] & North America & Descriptive prospective & Cryptococcosis & not & - \\
\hline 2015 & [15] & Belgium & Descriptive epidemiological & Pneumocystis pneumonia & yes & - \\
\hline 2015 & [43] & Czech Republic & Descriptive epidemiological & Pneumocystis pneumonia & yes & not \\
\hline 2015 & [16] & Denmark & Descriptive epidemiological & Pneumocystis pneumonia & yes & - \\
\hline 2015 & [44] & Mexico & Descriptive epidemiological & Pneumocystis pneumonia & yes & yes \\
\hline 2015 & [17] & Nepal & Descriptive epidemiological & Pneumocystis pneumonia & yes & not \\
\hline 2015 & [18] & Qatar & Descriptive epidemiological & Pneumocystis pneumonia & yes & - \\
\hline 2015 & [19] & Russia & Descriptive epidemiological & Pneumocystis pneumonia & not & - \\
\hline 2015 & [20] & Senegal & Descriptive epidemiological & Pneumocystis pneumonia & yes & not \\
\hline 2016 & [12] & South Africa & Randomized & Cryptococcosis & not & - \\
\hline 2016 & [21] & Kenya & Descriptive epidemiological & Pneumocystis pneumonia & yes & no \\
\hline 2016 & [13] & Mexico & Descriptive retrospective & Histoplasmosis & not & - \\
\hline 2017 & [22] & Philippines & Descriptive epidemiological & Pneumocystis pneumonia & yes & - \\
\hline 2017 & [23] & Chile & Descriptive epidemiological & Pneumocystis pneumonia & yes & - \\
\hline 2018 & [24] & Malaysia & Descriptive epidemiological & Pneumocystis pneumonia & yes & yes \\
\hline 2018 & [45] & Uruguay & Descriptive epidemiological & Pneumocystis pneumonia & yes & yes \\
\hline 2018 & [25] & Romania & Descriptive epidemiological & Pneumocystis pneumonia & yes & - \\
\hline 2018 & [26] & Jordan & Descriptive epidemiological & Pneumocystis pneumonia & yes & yes \\
\hline
\end{tabular}

${ }^{\star}$ Recurrent vulvovaginal candidiasis and oral candidiasis. -: They did not mention.

The most frequent IFI in people living with HIV was Pneumocystis (Table 2); only two studies highlighted cryptococcosis as the most frequent infection [10] [12], and one histoplasmosis as the most common severe fungal disease among people living with HIV [13]. In this last study, Histoplasma capsulatum was the most prevalent etiological agent (36 [27.2\%] of the 132 evaluated individuals) in Mexico, between 2005-2014, after Candida spp. Of the total, 83 patients (62.9\%) were infected by HIV [13]. However, this study neither pointed out whether the infection by $H$. capsulatum occurred only in people living with HIV nor mentioned the cases of Pneumocystis pneumonia. 
Table 2. Study characteristics in which Pneumocystis pneumonia was the most frequent IFI in people living with HIV.

\begin{tabular}{|c|c|c|}
\hline Year & Publications & Results (Pneumocystis pneumonia) \\
\hline 2009 & [14] & 297 people living with HIV. 131 cases of Pneumocystis pneumonia \\
\hline 2014 & {$[42]$} & $\begin{array}{l}35,876 \text { invasive fungal infections in the general population. } 26.1 \% \\
\text { cases of Pneumocystis pneumonia: majority in HIV carriers. }\end{array}$ \\
\hline 2015 & [15] & 15 cases/year \\
\hline 2015 & [43] & $\begin{array}{l}\text { Estimate: Pneumocystis pneumonia in } 40 \% \text { of HIV cases in } 2012 . \\
\text { Pneumocystis pneumonia in } 12 \text { of the } 30 \text { new cases of HIV. }\end{array}$ \\
\hline 2015 & [16] & 15 cases/year \\
\hline 2015 & [44] & Prevalence: $5,130 /$ year. \\
\hline 2015 & [17] & Estimate: $990 /$ year. Incidence: $3.6 / 100,000$ \\
\hline 2015 & [18] & 15 cases/year. Incidence: $0.8 / 100,000$ \\
\hline 2015 & [19] & 1,414 cases/year. Incidence: $0.99 / 100,000$ \\
\hline 2015 & [20] & 1,149 cases/year. Incidence: $8.2 / 100,000$ \\
\hline 2016 & [21] & 17,000 cases/year. Incidence: $43 / 100,000$ \\
\hline 2017 & [22] & 391 cases/year. Incidence: $0.40 / 100,000$ \\
\hline 2017 & [23] & 766 cases/year. Incidence: 4.3/100,000 \\
\hline 2018 & [24] & 1,286 cases/year. Incidence: $4.2 / 100,000$ \\
\hline 2018 & [45] & 48 cases/year. Incidence: $1.4 / 100,000$ \\
\hline 2018 & [25] & 30 cases/year. Incidence: $0.18 / 100,000$ \\
\hline 2018 & [26] & 6 cases/year. Incidence: $0.1 / 100,000$ \\
\hline
\end{tabular}

In the retrospective study conducted in North America, 159 (52.5\%) of 303 HIV carriers presented with cryptococcosis. Of these, $77.9 \%$ showed a CD4+ count of less than $50 \mathrm{cells} / \mathrm{mm}^{3}$ [10]. In research conducted in South Africa, where four $(12.0 \%)$ of the 34 patients necropsied presented with cryptococcosis, the CD4+ count ranged from 1 cells $/ \mathrm{mm}^{3}$ to $56 \mathrm{cells} / \mathrm{mm}^{3}$, and in two of these patients, Cryptococcus neoformans was identified [12].

Identification of the Cryptococcus species was described by three (15.0\%) studies [12] [13] [14]. In a study carried out in Mexico, 132 cases of fungal diseases were identified, of which 28 were caused by $C$. neoformans, one by $C$. laurentii, one by $C$. albidus, and one by $C$. uniguttulatus [13]. The studies carried out in Italy and South Africa identified only $C$. neoformans as the cryptococcal agent, which was responsible for 62 (20.9\%) of 297 cases of fungal infections and 4 (12.0\%) of 34 cases of fungal infections, respectively [12] [14]. The infection of the meninges (cryptococcal meningitis) was indicated in $12(60.0 \%)$ of the studies [15]-[26]. 


\section{Discussion}

The most common IFI among people living with HIV was Pneumocystis pneumonia. Despite the decline in mortality from HIV infection, Pneumocystis pneumonia is still a worrisome disease and, in most developing countries [27]. Pneumocystis pneumonia is caused by $P$. jirovecii and, in many cases, this disease defines AIDS in people living with HIV, occurring more often when the CD4+ count is less than 200 cells $/ \mathrm{mm}^{3}$ and when the patient was not using antiretrovirals [10] [21] [28] [29] [30].

Candidiasis was the fungal infection (although it is not invasive) that stood out in most studies evaluated due to its high prevalence. According to literature, oropharyngeal candidiasis is still a common problem in the people living with HIV, even with the availability of HAART [31]. Esophageal candidiasis affects about $20 \%$ of AIDS patients not using antiretrovirals and $5 \%$ of those who are under antiretroviral therapy [20]. Candidiasis can become severe when it spreads to deep organs and causes candidemia, increasing the mortality rate.

Cryptococcosis, the second most frequent IFI in people living with HIV, has a relevant role, because it is considered one of the most common mycoses, especially affecting the central nervous system [31]. Cryptococcal meningitis emerged firstly as one of the main causes of infectious morbidity and mortality in patients with AIDS, since the beginning of the spread of HIV in the world [32]. In the last two decades, there have been advances in the prevention, diagnosis, therapy, and results of patients with cryptococcal meningitis. However, efforts are still needed in order to implement these strategies, mainly in low-income populations [33]. The low incidence of cryptococcal meningitis found in some countries such as Romania, which has an estimated rate of 0.09/100,000 inhabitants, may have as a justification the broad coverage of HAART [25].

Histoplasmosis, an infection caused by $H$. capsulatum, first presents an acute pulmonary form, from where the fungus spreads through the hematogenic pathway. Disseminated histoplasmosis was rare until the emergence of AIDS, occurring only at extremes of age and in individuals immunocompromised by neoplastic diseases or by the use of immunosuppressant therapy [34]. However, the annual incidence of histoplasmosis is still unknown in many countries, even if endemic [35].

Disseminated histoplasmosis was observed in 23 patients, of which 12 (52.2\%) presented with HIV/histoplasmosis coinfection, among patients admitted in a hospital of high complexity in Mato Grosso do Sul, State of the Central-Western region of Brazil from 2011 to 2016. The average CD4+ count was 19 cells $/ \mathrm{mm}^{3}$, and $56.5 \%$ of the patients died [36]. Another study conducted in a university hospital in the interior of the state of Minas Gerais, Brazil, highlighted 113 cases of histoplasmosis in 20 years, and of them, 103 (91.1\%) were associated with AIDS [37].

HAART have improved the cellular immunity of AIDS patients, and also the rate of response to the treatment of histoplasmosis, as observed in a study con- 
ducted in Colombia, by Tobón et al. [38]. In this study, all who received HAART responded to the antifungal treatment as well as the non-HIV patients, compared with $47 \%$ among those who did not receive antiretroviral therapy [38]. HAART has an important impact on reducing mortality, vertical transmission, and treatment of serious comorbidities [31]. For instance, a study carried out in China from 2014 to 2015 evaluated 954 HIV infected patients and concluded that the two most important factors for hospital mortality were the CD4+ count $<100$ cells $/ \mathrm{mm}^{3}$ and the non-use of HAART [39]. To promote restoration of the immune system is important for the treatment and prevention of all types of infection.

Early diagnosis of any type of infectious disease is extremely important for proper treatment. Delayed diagnostic of fungal diseases exacerbates the problem of empirical use of antimicrobials, with consequent risk of increased antimicrobial-resistant microorganisms [40]. The diagnosis of a fungal disease, especially in an immunocompromised patient, is not always obvious. It depends on the local epidemiology, the technical capacity of the healthcare team, the availability of diagnostic tests, whether serological, microscopic and culture, or molecular tests, such as PCR. The causes of death in patients with aids are tuberculosis and other associated infections, as fungal, bacterial or toxoplasmosis, and a team prepared for these diagnoses is not always available in all countries, especially in developing ones [41].

Most of the studies reported lack of reliable data and records on the frequency of IFI. Even with the limitation of epidemiological data, there is high mortality among people living with HIV related mainly to one of the following IFI: cryptococcosis, Pneumocystis pneumonia, histoplasmosis, or aspergillosis, which can be significantly reduced by investment in timely diagnosis and appropriate antifungal treatment [35].

Even in the current world effort scenario to increase access to HAART [1], it is necessary to improve the registration of IFI so that we can have access to actual data of these diseases in the population in addition to the greater availability of appropriate diagnostic and therapeutic methods. As a result, IFI can be identified early and have correct handling, which is important in preventing related mortality caused by fungi in people living with HIV [35].

In addition to the findings, opportunistic fungal infections affect not only HIV/AIDS patients, but also others who have immunocompromised, such as patients with hematological diseases, solid organ transplant and chronic obstructive pulmonary disease, among others [7]. Often infections by $P$. jirovecii are confused with other lung diseases, and as the microbiological diagnosis by culture is not performed, it can often not be confirmed, which may mask their real prevalence. Other fungi that affect HIV/AIDS-infected patients, such as Aspergillus species and Talaromyces marneffei species [7] [8] are often forgotten. We believe that studies on fungi that affect this population that is more susceptible to opportunistic fungal infections are poorly disseminated, or are restricted to 
regional publications. Thus, access to the literature is not possible, and the real prevalence of the different etiologic agents involved may remain unknown.

\section{Conclusion}

Invasive fungal infections are associated with greater morbidity and mortality in immunocompromised individuals. In most of the studies evaluated, the most frequent IFI in people living with HIV was caused by Pneumocystis jirovecii. However, there is a lack of reliable data regarding its frequency, as well as for other fungal infections, like histoplasmosis. There is a need for further studies to assess the frequency of IFI in people living with HIV, which may serve as subsidies for the implementation of strategies for the prevention and management, in order to improve the quality of life and reduction of morbidity and mortality in this population.

\section{Acknowledgements}

The authors would like to thank Coordenação de Aperfeiçoamento de Pessoal de Nível Superior-Brazil (CAPES)_Financial Code 001.

\section{Conflicts of Interest}

The authors declare no conflicts of interest regarding the publication of this paper.

\section{References}

[1] UNAIDS (2017) Joint United Nations Programme on HIV/AIDS (UNAIDS). UNAIDS Data 2017.

http://www.unaids.org/sites/default/files/media_asset/20170720_Data_book_2017_e $\underline{\text { n.pdf }}$

[2] Wang, H., Wolock, T.M., Carter, A., Nguyen, G., Kyu, H.H., Gakidou, E., Coates, M.M., et al. (2016) Estimates of Global, Regional, and National Incidence, Prevalence, and Mortality of HIV, 1980-2015: The Global Burden of Disease Study 2015. The Lancet HIV, 3, e361-e387. https://doi.org/10.1016/S2352-3018(16)30087-X

[3] UNAIDS (2019) Joint United Nations Programme on HIV/AIDS (UNAIDS). Communities at the Centre: Defending Rights, Breaking Barriers, Reaching People with HIV Services.

https://www.unaids.org/sites/default/files/media_asset/2019-global-AIDS-update_e $\underline{\text { n.pdf }}$

[4] Brazil (2018) Ministério da Saúde. Secretaria de Vigilância em Saúde. Departamento de Vigilância, Prevenção e Controle das Infecções Sexualmente Transmissíveis, do HIV/Aids e das Hepatites Virais. Protocolo clínico e diretrizes terapêuticas para manejo da infecção pelo HIV em adultos. Brasília-DF. http://portalms.saude.gov.br/protocolos-e-diretrizes

[5] Brown, G.D., Denning, D.W., Gow, N.A., Levitz, S.M., Netea, M.G. and White, T.C. (2012) Hidden Killers: Human Fungal Infections. Science Translational Medicine, 4, 165rv13. https://doi.org/10.1126/scitranslmed.3004404

[6] Brown, G.D., Denning, D.W. and Levitz, S.M. (2012) Tackling Human Fungal Infections. Science, 336, 647. https://doi.org/10.1126/science.1222236 
[7] Armstrong-James, D., Bicanic, T., Brown, G.D., Hoving, J.C., Meintjes, G. and Nielsen, K. (2017) AIDS-Related Mycoses: Current Progress in the Field and Future Priorities. Trends in Microbiology, 25, 428-430. https://doi.org/10.1016/j.tim.2017.02.013

[8] Limper, A.H., Adenis, A., Le, T. and Harrison, T.S. (2017) Fungal Infections in HIV/AIDS. The Lancet Infectious Diseases, 17, e334-e343. https://doi.org/10.1016/S1473-3099(17)30303-1

[9] Paramythiotou, E., Frantzeskaki, F., Flevari, A., Armaganidis, A. and Dimopoulos, G. (2014) Invasive Fungal Infections in the ICU: How to Approach, How to Treat. Molecules, 19, 1085-1119. https://doi.org/10.3390/molecules19011085

[10] Marukutira, T., Huprikar, S., Azie, N., Quan, S.P., Meier-Kriesche, H.U. and Horn, D.L. (2014) Clinical Characteristics and Outcomes in 303 HIV-Infected Patients with Invasive Fungal Infections: Data from the Prospective Antifungal Therapy Alliance Registry, a Multicenter, Observational Study. HIVIAids, 6, 39-47. https://doi.org/10.2147/HIV.S53910

[11] Mendes, K.D.S., Silveira, R.C.D.C.P. and Galvão, C.M. (2008) Revisão integrativa: Método de pesquisa para a incorporação de evidências na saúde e na enfermagem. Texto \& Contexto Enfermagem, 17, 758-764. (In Portuguese) https://doi.org/10.1590/S0104-07072008000400018

[12] Karat, A.S., Omar, T., Von Gottberg, A., Tlali, M., Chihota, V.N., Churchyard, G.J., Wolter, N., et al. (2016) Autopsy Prevalence of Tuberculosis and Other Potentially Treatable Infections among Adults with Advanced HIV Enrolled in Out-Patient Care in South Africa. PLoS ONE, 11, e0166158. https://doi.org/10.1371/journal.pone.0166158

[13] Gaona-Flores, V.A., Campos-Navarro, L.A., Cervantes-Tovar, R.M. and Alcalá-Martínez, E. (2016) The Epidemiology of Fungemia in an Infectious Diseases Hospital in Mexico City: A 10-Year Retrospective Review. Sabouraudia, 54, 600-604. https://doi.org/10.1093/mmy/myw017

[14] Antinori, S., Nebuloni, M., Magni, C., Fasan, M., Adorni, F., Viola, A., Corbellino, M., Galli, M., Vago, G., Parravicini, C. and Ridolfo, A.L. (2009) Trends in the Postmortem Diagnosis of Opportunistic Invasive Fungal Infections in Patients with AIDS: A Retrospective Study of 1,630 Autopsies Performed between 1984 and 2002. American Journal of Clinical Pathology, 132, 221-227. https://doi.org/10.1309/AJCPRAAE8LZ7DTNE

[15] Lagrou, K., Maertens, J., Van Even, E. and Denning, D.W. (2015) Burden of Serious Fungal Infections in Belgium. Mycoses, 58, 1-5. https://doi.org/10.1111/myc.12389

[16] Mortensen, K.L., Denning, D.W. and Arendrup, M.C. (2015) The Burden of Fungal Disease in Denmark. Mycoses, 58, 15-21. https://doi.org/10.1111/myc.12383

[17] Khwakhali, U.S. and Denning, D.W. (2015) Burden of Serious Fungal Infections in Nepal. Mycoses, 58, 45-50. https://doi.org/10.1111/myc.12393

[18] Taj-Aldeen, S.J., Chandra, P. and Denning, D.W. (2015) Burden of Fungal Infections in Qatar. Mycoses, 58, 51-57. https://doi.org/10.1111/myc.12386

[19] Klimko, N., Kozlova, Y., Khostelidi, S., Shadrivova, O., Borzova, Y., Burygina, E., Denning, D.W., et al. (2015) The Burden of Serious Fungal Diseases in Russia. Mycoses, 58, 58-62. https://doi.org/10.1111/myc.12388

[20] Badiane, A.S., Ndiaye, D. and Denning, D.W. (2015) Burden of Fungal Infections in Senegal. Mycoses, 58, 63-69. https://doi.org/10.1111/myc.12381

[21] Guto, J.A., Bii, C.C. and Denning, D.W. (2016) Estimated Burden of Fungal Infec- 
tions in Kenya. The Journal of Infection in Developing Countries, 10, 777-784. https://doi.org/10.3855/jidc.7614

[22] Batac, M.C.R. and Denning, D. (2017) Serious Fungal Infections in the Philippines. European Journal of Clinical Microbiology \& Infectious Diseases, 36, 937-941. https://doi.org/10.1007/s10096-017-2918-7

[23] Duarte, E.A. and Denning, D.W. (2017) Serious Fungal Infections in Chile. European Journal of Clinical Microbiology \& Infectious Diseases, 36, 983-986. https://doi.org/10.1007/s10096-017-2925-8

[24] Velayuthan, R.D., Samudi, C., Lakhbeer Singh, H.K., Ng, K.P., Shankar, E.M. and Denning, D.W. (2018) Estimation of the Burden of Serious Human Fungal Infections in Malaysia. Journal of Fungi, 4, 38. https://doi.org/10.3390/jof4010038

[25] Mareș, M., Moroti-Constantinescu, V.R. and Denning, D.W. (2018) The Burden of Fungal Diseases in Romania. Journal of Fungi, 4, 31. https://doi.org/10.3390/jof4010031

[26] Wadi, J. and Denning, D.W. (2018) Burden of Serious Fungal Infections in Jordan. Journal of Fungi, 4, 15. https://doi.org/10.3390/jof4010015

[27] Morris, A., Lundgren, J.D., Masur, H., Walzer, P.D., Hanson, D.L., Frederick, T., Kaplan, J.E., et al. (2004) Current Epidemiology of Pneumocystis Pneumonia. Emerging Infectious Diseases, 10, 1713-1720. https://doi.org/10.3201/eid1010.030985

[28] Masur, P.B.H., Kaplan, J.E. and Holmes, K.K. (2002) Guidelines for Preventing Opportunistic Infections among HIV-Infected Persons-2002: Recommendations of the US Public Health Service and the Infectious Diseases Society of America. Annals of Internal Medicine, 37, 435-478. https://doi.org/10.7326/0003-4819-137-5_Part_2-200209031-00002

[29] Cheng, C.Y., Chen, M.Y., Hsieh, S.M., Sheng, W.H., Sun, H.Y., Lo, Y.C., Hung, C.C., et al. (2010) Risk of Pneumocystosis after Early Discontinuation of Prophylaxis among HIV-Infected Patients Receiving Highly Active Antiretroviral Therapy. BMC Infectious Diseases, 10, 126. https://doi.org/10.1186/1471-2334-10-126

[30] Dixit, A., Shariff, R., Gandham, S., Bhavsar, R., Mantis, J. and Vapnyar, V. (2018) Recurrent Pneumocystis Pneumonia with Uncommon Radiographic Presentation. Cureus, 10, e2125. https://doi.org/10.7759/cureus.2125

[31] Armstrong-James, D., Meintjes, G. and Brown, G.D. (2014) A Neglected Epidemic: Fungal Infections in HIV/AIDS. Trends in Microbiology, 22, 120-127. https://doi.org/10.1016/j.tim.2014.01.001

[32] Mitchell, T.G. and Perfect, J.R. (1995) Cryptococcosis in the Era of AIDS-100 Years after the Discovery of Cryptococcus neoformans. Clinical Microbiology Reviews, 8, 515-548. https://doi.org/10.1128/CMR.8.4.515

[33] Chammard, T.B., Temfack, E., Lortholary, O. and Alanio, A. (2018) Diagnostic and Therapeutic Strategies in Cryptococcosis: Impact on Outcome. Memorias do Instituto Oswaldo Cruz, 113, e180050. https://doi.org/10.1590/0074-02760180050

[34] Borges, A.S., Ferreira, M.S., Silvestre, M.T., Nishioka, S.A. and Rocha, A. (1997) Histoplasmosis in Immunodepressed Patients: Study of 18 Cases Seen in Uberlandia, MG. Revista da Sociedade Brasileira de Medicina Tropical, 30, 119-124. https://doi.org/10.1590/S0037-86821997000200006

[35] Denning, D.W. (2016) Minimizing Fungal Disease Deaths will Allow the UNAIDS Target of Reducing Annual Aids Deaths below 500000 by 2020 to Be Realized. Philosophical Transactions of the Royal Society B: Biological Sciences, 371, Article ID: 20150468. https://doi.org/10.1098/rstb.2015.0468 
[36] Boigues, B.C.S., Paniago, A.M.M., Lima, G.M.E., Nunes, M.D.O. and Uehara, S.N.D.O. (2018) Clinical Outcomes and Risk Factors for Death from Disseminated Histoplasmosis in Patients with AIDS Who Visited a High-Complexity Hospital in Campo Grande, MS, Brazil. Revista da Sociedade Brasileira de Medicina Tropical, 51, 155-161. https://doi.org/10.1590/0037-8682-0369-2017

[37] Borges, A.S. and Ferreira, M.S. (2009) Histoplasmosis. Revista da Sociedade Brasileira de Medicina Tropical, 42, 192-198. https://doi.org/10.1590/S0037-86822009000200020

[38] Tobón, A.M., Agudelo, C.A., Rosero, D.S., Ochoa, J.E., De Bedout, C., Zuluaga, A., Restrepo, A., et al. (2005) Disseminated Histoplasmosis: A Comparative Study between Patients with Acquired Immunodeficiency Syndrome and Non-Human Immunodeficiency Virus-Infected Individuals. The American Journal of Tropical Medicine and Hygiene, 73, 576-582. https://doi.org/10.4269/ajtmh.2005.73.576

[39] Pang, W., Shang, P., Li, Q., Xu, J., Bi, L., Zhong, J. and Pei, X. (2018) Prevalence of Opportunistic Infections and Causes of Death among Hospitalized HIV-Infected Patients in Sichuan, China. The Tohoku Journal of Experimental Medicine, 244, 231-242. https://doi.org/10.1620/tjem.244.231

[40] Denning, D.W., Perlin, D.S., Muldoon, E.G., Colombo, A.L., Chakrabarti, A., Richardson, M.D. and Sorrell, T.C. (2017) Delivering on Antimicrobial Resistance Agenda Not Possible without Improving Fungal Diagnostic Capabilities. Emerging Infectious Diseases, 23, 177-183. https://doi.org/10.3201/eid2302.152042

[41] Bongomin, F., Govender, N.P., Chakrabarti, A., Robert-Gangneux, F., Boulware, D.R., Zafar, A., Bazira, J., et al. (2019) Essential in Vitro Diagnostics for Advanced HIV and Serious Fungal Diseases: International Experts' Consensus Recommendations. European Journal of Clinical Microbiology \& Infectious Diseases, 38, 1581-1584. https://doi.org/10.1007/s10096-019-03600-4

[42] Bitar, D., Lortholary, O., Le Strat, Y., Nicolau, J., Coignard, B., Tattevin, P., Dromer, F., et al. (2014) Population-Based Analysis of Invasive Fungal Infections, France, 2001-2010. Emerging Infectious Diseases, 20, 1149. https://doi.org/10.3201/eid2007.140087

[43] Chrdle, A., Mallátová, N.A., Vašáková, M., Haber, J. and Denning, D.W. (2015) Burden of Serious Fungal Infections in the Czech Republic. Mycoses, 58, 6-14. https://doi.org/10.1111/myc.12384

[44] Corzo-León, D.E., Armstrong-James, D. and Denning, D.W. (2015) Burden of Serious Fungal Infections in Mexico. Mycoses, 58, 34-44.

https://doi.org/10.1111/myc.12395

[45] Macedo-Viñas, M. and Denning, D.W. (2018) Estimating the Burden of Serious Fungal Infections in Uruguay. Journal of Fungi, 4, 37.

https://doi.org/10.3390/jof4010037 